\title{
YouTube viewers in diapers: An exploration of factors associated with amount of toddlers' online viewing
}

\author{
Nelly Elias \& Idit Sulkin \\ Department of Communication Studies, Ben-Gurion University of the Negev, Beer-Sheva, Israel
}

\begin{abstract}
Recent studies show that television is no longer the primary choice for screen viewing among very young children, having been surpassed by online viewing platforms, among which YouTube is dominant. YouTube's simple user interface, that allows even toddlers to proceed to the next item on the playlist and affords them easy access to their favorite videos, has been suggested as the key to its popularity with very young audiences. On the other hand, young children's lack of technical, critical and social skills renders them particularly vulnerable to commercial and age-inappropriate content that they might encounter online. In this rapidly changing media environment, in which more and more children begin online activity at a much younger age, it is crucial to evaluate the amount of young children's online viewing and the factors that determine their viewing habits. Consequently, the present study aimed at identifying the profile of toddler online viewers based on child, parent and family-related characteristics and revealing predictors that might explain higher online exposure. The study, based on a face-to-face survey conducted in Israel among 289 parents of toddlers aged 18-36 months, reveals that online viewing has become normative behavior among toddlers and emphasizes how deeply online viewing is integrated into the basic daily routine of parents with very young children who use online viewing platforms to fulfill a wide range of their childrearing needs.
\end{abstract}

Keywords: Toddlers; online viewing; YouTube; childrearing needs

\section{Introduction}

Screen viewing has become normative behavior for infants and toddlers. According to recent estimates, on a typical day, children up to age 24 months watch screen media for about 1-2 hours and children aged 2-5 years for over three hours (Vaala \& Hornik, 2014; Wartella, Rideout, Lauricella, \& Connell, 2013). Although television still dominates toddlers' and preschoolers' screen time, a contemporary survey conducted in the United States indicates that in households in which touchscreen devices are available, television is no longer the primary choice for screen viewing among very young children, but has been surpassed by online viewing platforms such as Netflix and YouTube (Miner, 2015).

According to Holloway, Green and Livingstone (2013), watching video clips online is among the earliest internet activities carried out by very young children, resulting in high popularity of YouTube channels targeting toddlers and preschoolers. For example, YouTube's Sesame Street channel recently reached a billion views (Luckerson, 2013) and a TUTiTu channel (owned by a small animation company targeting infants and toddlers) was ranked $40^{\text {th }}$ among YouTube's 100 most viewed channels (Fox, 2014). YouTube's simple user interface, that allows even toddlers to proceed to the next item on the playlist and affords them easy access to favorite videos that can be watched again and again, has been suggested as the key to its popularity with very young audiences (Buzzi, 2011). It is thus not surprising that producers of content targeting toddlers and preschoolers soon discovered 
YouTube's appeal and began using it as a major content promotion platform by uploading complete episodes or short clips of programs broadcast on television channels (Elias, Sulkin, \& Lemish, in press; Grossaug, 2017).

Besides providing an extensive variety of content produced specifically for young children, YouTube has also spawned new formats in children's entertainment that once baffled people outside their target audiences (Dredge, 2015). Young children appear to be attracted to particular types of content, many of which are based on comic situations, such as challenges (e.g., tasting hot pepper) and silly skits (e.g., a person in a rooster costume surprising a police officer). Topping the list of children's favorites, however, are unboxing videos, in which boxes containing different products are opened (Knorr, 2016). According to Marsh (2016), the attraction of unboxing may lie in the mystery of the unwrapping process. Young children enjoy mystery and suspense, especially when it is likely to have safe and predictable outcomes. One prime example of this trend is a series of YouTube videos in which a person opens Kinder Surprise Eggs, with hundreds of millions of hits. Although no data are available regarding the viewers' ages, Jordan (2015) maintains that such videos are particularly appealing to children aged 2-4 because they expose them to shape transformation, thereby gratifying a developmental need characteristic of this age group.

Notwithstanding its benefits, YouTube also has significant drawbacks as a source of children's entertainment. When the YouTube Kids application was launched, Google declared it to be a safe and educational media environment for the very young, equipped with a safety mode for automatic filtering of content marked as inappropriate. The result, however, fell far short of fulfilling Google's promise and YouTube Kids has been criticized heavily for its lack of professional selection and display of commercial content, ignoring the wellestablished advertising safeguards adopted by both broadcast and cable television (Golin, Chester, \& Campbell, 2015; Luscombe, 2015).

The situation on other YouTube channels available for young children is even more disturbing. First, the transmission of child-oriented content is interrupted frequently by automatic advertisements, many of which are inappropriate for younger viewers. Moreover, a recent report on children's safety on YouTube shows that very young children are only 2-4 clicks away from adult content while watching children-oriented videos. For example, children watching Sesame Street are two clicks from a car accident video, while those viewing Dora the Explorerare four clicks from a video featuring swearing and nudity (Kaspersky Lab, 2013). Furthermore, numerous recent media reports address the increasing popularity of amateur live action videos that bear innocent tags using names of children's most popular heroes, such as Elsa and Anna (from the movie Frozen) or Spiderman, but contain offensive content and present explicit expressions of sexual behavior, vandalism and violence. These videos very easily find their way into the suggested YouTube playlists of episodes from the favorite children's shows and gain popularity as millions of people view them (Mako magazine, 2016; Sol, 2017).

In this rapidly changing media environment, in which more and more children begin online activity at a very young age and are exposed to a wide variety of online content (Holloway et al., 2013), it is crucial to evaluate the amount of young children's online viewing and the factors that determine children's online viewing habits. Although young children's screen viewing has been investigated extensively, most studies focused on television viewing or on total screen time, without differentiating among viewing platforms. Moreover, those studies that did examine online viewing usually addressed a broad age cohort, such as 0-8 or 2-12 (e.g., Buzzi, 2011; Holloway et al., 2013; Miner, 2015), thus overlooking important developmental differences among infants, toddlers, preschoolers and older children.

In this regard, we claim that the growing popularity of online viewing among children younger than three evokes special concern. First, the easy accessibility of online content enables screen viewing at any time and place, possibly increasing children's total media exposure. Second, the content that young children watch online can be created and uploaded by virtually anyone and is not regulated by professional production procedures. This observation is especially important considering young children's lack of technical, critical and social skills, rendering them particularly vulnerable to unsupervised online viewing (Livingstone, Haddon, Görzig, \& Ólafsson, 2011).

Accordingly, this study focuses specifically on toddlers - children up to three years old who were largely neglected in the previous studies - aiming at estimating the amount of their online viewing (AOV) and to identify 
factors associated with higher online exposure. The study was conducted in Israel, an industrialized country with a very high penetration of internet and touchscreen media in its households (Man \& Lev-On, 2015; Nimrod, Adoni, \& Nossek, 2015). Israel is also a pioneer in programming for infants and toddlers. Today, all Israeli producers and broadcasters of young children's programs preserve a strong presence on YouTube, where they upload their content in the packages specifically adapted for online viewing. Moreover, according to the internal reports of major children's channels, many programs targeting toddlers are watched more on YouTube than via television (Elias et al., in press; Grossaug, 2017). Online viewing thus appears to be a highly accessible choice for Israeli parents with young children, rendering them particularly relevant to examination of online viewing among toddlers.

\section{Young Children's Online Viewing}

Focus on toddlers' online viewing is of particular interest because children of this age experience a major transformation from infants fully dependent on their parents for their viewing menu to assertive media consumers with specific preferences and tastes (Cantor \& Cornish, 2016; Schmitt, 2001). Furthermore, constantly improving cognitive and motor skills enable toddlers to engage well with touchscreen devices and use them for online activities (Holloway et al., 2013; Kucirkova, 2011; Zack \& Barr, 2016). Recent studies conducted in several European countries indicate that between $50 \%$ to $70 \%$ of children aged 3-6 use the internet on a regular basis and that video sharing sites are among the first that very young children visit (Holloway et al., 2013).

In the United Kingdom, for example, the relevant literature shows that YouTube is the top-rated app among children aged 0-8 and that use of mobile devices for watching videos on YouTube is a common digital literacy practice among children aged 3-4 (Livingstone, Marsh, Plowman, Ottovordemgentschenfelde, \& Fletcher-Watson, 2014; Marsh, Hannon, Lewis, \& Ritchie, 2017; Stephen, Stevenson, \& Adey, 2013). Furthermore, a study conducted in Italy among 106 parents of children aged 2-12 shows that $65 \%$ of children in the sample watch YouTube at least several times a week (Buzzi, 2011). A more recent survey conducted in the United States, using a much larger sample of 800 parents, displays a similar pattern, in which 57\% of children aged 2-12 prefer devices other than television for viewing video content (Miner, 2015). These studies, however, do not focus specifically on the viewing habits of children younger than three. The question of whether these trends are typical of toddlers as well thus remains open.

Toddlers' online viewing rates may increase concomitantly with the growing popularity of touchscreen media devices (i.e., smartphones and tablets) among this audience. The introduction of the iPhone in 2007 marked the birth of the digitods - a new generation of children born with ready access to a vast range of touchscreen internet connected devices (Holloway, Green \& Stevenson, 2015). In 2011, a survey conducted in the United States found that $10 \%$ of children under two used a touchscreen mobile device; two years later, the percentage rose to 38\% (Rideout, 2013). Another study, carried out in the United Kingdom in 2015, shows that $75 \%$ of children aged between six months and three years used a touchscreen on a daily basis, increasing from $51 \%$ at 6-11 months to $92 \%$ at 25-36 months (Cheung, Bedford, Saez De Urabain, \& Karmiloff-Smith, 2017). Accordingly, touchscreens have become the new "playmate, teacher and babysitter" for very young children (Cantor \& Cornish, 2016, p. 8), whether at home or outdoors (Hiniker, Suh, Cao, \& Kientz, 2016; Radesky et al., 2014).

Factors affecting parents' decisions to allow their very young children to watch online content should be examined as well, as previous studies addressed parents of children in various age cohorts, without specific reference to toddlers (see, e.g., Nikken \& de Haan, 2015), who require special research attention for various reasons. First, this period is characterized by high parental involvement in children's viewing experiences. Hence, parents' attitudes toward media would play an important role in shaping their young children's online viewing habits. Moreover, toddlerhood is a very challenging time for parents, even more so than infancy (Morrongiello, Corbett, McCourt, \& Johnston, 2006; Vaala \& Hornik, 2014). It constitutes a period of rapidly improving mobility that demands constant alertness, not to mention the well-known "terrible twos" stage that is associated with defiant behavior and temper tantrums (DeHart, Sroufe, \& Cooper, 2004). The daily challenges confronted by toddlers' parents result in frequent use of screen media (many of which are mobile and online) as an integral part of their parenting practices (Hiniker et al., 2016; Kabali et al., 2015). The effects of parents' attitudes and childrearing needs on toddlers' AOV thus call for a thorough empirical investigation. 


\section{Factors Associated with Young Children's Screen Viewing}

Considering the paucity of academic inquiry into toddlers' online habits, this section summarizes insights from the related fields of children's screen viewing and online safety. Previous studies on factors explaining children's overall screen time revealed that the family system plays a central role in shaping youngsters' viewing habits. As such, an extensive range of characteristics concerning the family unit - and parents in particular - should be taken into account in attempting to explain the extent of young children's online exposure (Gentile \& Walsh, 2002; Jordan, 2004).

First, children's total screen time is associated with the structural features of family life and sociodemographic characteristics. For example, the number of TV sets at home correlates positively with children's screen time (Johnson, Chen, Hughes, \& O'Connor, 2015; Vaala, Bleakley, \& Jordan, 2013), as does mother's employment (Vaala \& Hornik, 2014). Parents' education associates negatively with children's screen time, as children with less educated parents watch more screen media (Anand \& Krosnick, 2005). Although very little is known about correlations between children's online viewing and family characteristics, recent studies show that older siblings make it easier for very young children to start using the internet (Holloway et al., 2013).

No less important is the role of parental attitudes in shaping their young children's viewing habits. Studies on children's total screen time have found that parents who believe that screen viewing is an opportunity for enrichment allow their children to watch more screen media (Vaala et al., 2013; Vaala \& Hornik, 2014; Vandewater \& Lee, 2009). Studies conducted to date on parents' attitudes to children's online habits primarily concern parental awareness of their children's online safety, ignoring the possible effect of parental attitudes on online viewing time. In general, the literature reveals that parents are less concerned about their younger children's internet use than that of their older ones, as they assume that the former's viewing is limited to suggested videos appropriate for their age group (Chaudron, 2015; Holloway et al., 2013; Plowman, McPake, \& Stephen, 2010). Moreover, parents tend to consider their young children's independent use of YouTube as desirable behavior attesting to their technological skills, displaying little awareness of the offensive content that might be only a few clicks away from children's favorite shows (Livingstone et al., 2014).

Furthermore, the growing share of YouTube in young children's viewing menus raises questions regarding parental mediation of online viewing. On the one hand, we need to examine the relationship between parents' tendency towards restrictive mediation and children's online viewing - a particularly crucial issue considering the high probability of children's exposure to inappropriate content. On the other hand, the variety of new formats and of intriguing and thought-provoking content available online might encourage parents to employ instructive mediation more often. So far, most empirical efforts have been devoted to issues concerning children's online safety (e.g., Hasebrink, Görzig, Haddon, Kalmus, \& Livingstone, 2011; Livingstone et al., 2011), parental restrictions regarding children's internet use (e.g., Dürager, \& Livingstone, 2012; Ofcom, 2014) and parent-child co-use of touchscreen devices (e.g., Zack \& Barr, 2016; Zaman, Nouwen, Vanattenhoven, de Ferrerre, \& Van Looy, 2016), whereas only a few studies have dealt directly with parental mediation of online viewing.

In this regard, Buzzi (2011) found that one third of parents of children aged 2-12 acknowledged that their children have accessed inappropriate content on YouTube. At the same time, however, most parents expressed the belief that they can monitor their children's online viewing "sufficiently" while carrying out other activities. Furthermore, Hiniker and colleagues' (2016) study on the screen viewing of children aged 14 months to 5.5 years sheds some light on parental assessment of the technological pros and cons of using YouTube as part of their restrictive mediation efforts. For example, parents spoke out against autoplay and suggested video features that make it more difficult to identify the transition point at which one video ends and another is about to begin. On the other hand, parents mentioned that YouTube Kids allows them to set more effective limits on their children's viewing time because the built-in stopping points serve as a kind of "third-party" restrictive mediation. These findings, however, only point to specific mediation practices employed by parents, while the manner in which different mediation styles affect the amount of online exposure remains unclear.

Finally, young children's online viewing may also be affected by their parents' childrearing routines. Research literature on overall screen time among toddlers and preschoolers shows that parents' instrumental needs, such as using the screen as a "babysitter" or as a parental aid during meals or before bedtime, proved to have a 
significant effect on the amount of their children's screen viewing (Beyens \& Eggermont, 2014; Piotrowski, Jordan, Bleakley, \& Hennessy, 2015). Parents' needs may be no less relevant regarding online viewing - an assumption partially supported by recent studies on parental use of touchscreens as digital pacifiers or shut-up toys to keep children occupied and calm them down in public places (Holloway, Green, \& Love, 2014; Kabali et al., 2015; Wartella et al., 2013). Along with the above findings pointing to YouTube's high popularity among very young viewers, we may assume, therefore, that when parents need an immediately available babysitter or time filler solution for their young children, online viewing of favorite content may well be their first choice.

Considering the above observations, the present study seeks to estimate the amount of toddlers' online viewing (AOV) for the first time and to identify the factors associated with higher online exposure, while attempting to answer the following questions:

RQ1: What is the connection between AOV and the characteristics of the child, parents and family as a whole?

RQ2: How is AOV associated with parental attitudes towards media effects and their preferences for specific viewing platforms?

RQ3: What is AOV's relationship to parental mediation styles?

RQ4: How is AOV associated with parental uses of screen viewing as part of their childrearing routine?

RQ5: What predictors explain AOV when examined simultaneously within a linear regression?

\section{Method}

The study is based on a face-to-face survey conducted in Israel among 289 parents of toddlers aged 18-36 months. The survey took place at the homes of the participants, who were selected according to two sampling methods, snowball and quota, in an attempt to ensure similar representation of boys and girls and of the three age cohorts (18-24, 24-30 and 30-36 months). In households with two children in the designated age range, the responding parent was asked to relate to the child whose next birthday is closer to the date of the survey.

To recruit the sample, we asked undergraduate students in four different mass communications classes for contact details of their relatives and acquaintances who were parents of toddlers. Trained research assistants phoned these parents to explain the study's goals, confirm participation and determine a survey date. About a week after calling, the research staff visited the participants' homes to conduct the approximately 30-minute survey. All participants signed a consent form prior to participation in the survey and received compensation of 10 Euros for their time. Full anonymity was ensured.

\section{Sample}

Children's average age was 26 months; $48 \%$ were girls. The average number of children per family was two. Half of the children (51\%) had at least one older sibling. Parents' average age was 32; 85\% were mothers. $44 \%$ of parents finished high school, 39\% had bachelor's degrees and 17\% had master's degrees or higher. A majority of parents (94\%) were employed. Among mothers, 68\% worked full time and 25\% worked part time. Among fathers, $93 \%$ worked full time and the rest part time. Although a non-random sampling method was applied, the participants' major demographic characteristics were typical of parents with young children in Israel's nonorthodox Jewish population (Israel Central Bureau of Statistics, 2011). Most families had access to a variety of screen media with internet connection: All families had at least one smartphone, 98\% - at least one PC and/or laptop, $57 \%$ - at least one tablet and $27 \%$ had a streaming media player. In $39 \%$ of families, the relevant child had a TV set in her/his bedroom. 


\section{Measures}

The structured questionnaire was inspired by previous studies on children's screen viewing (e.g., Jordan, Hersey, McDivitt, \& Heitzler, 2006; Rideout, 2013; Rideout \& Hammel, 2006; Wartella et al., 2013) and tested in a pilot study among ten volunteers whose characteristics matched those of the research population. The pilot study helped us clarify and improve the research tool, adjusting it to the specific conditions of toddlers' parents. The final version included the following categories: Children's amount of online viewing and of total screen viewing on a typical day, characteristics of children, parents and families, parents' preferences and concerns regarding children's media use, parents' mediation styles and their use of screen media as part of their childrearing routines.

Children's amount of online viewing (AOV; the dependent variable) was evaluated according to the viewing time on a typical day via different internet-connected devices (PC/laptop, tablet, smartphone and streaming device) ( $M=46.8$ minutes, $S D=45$ minutes).

Child's characteristics. Age in months $(M=26 ; S D=6.8)$; gender ( $48 \%$ were girls); total screen time on a typical day in minutes $(M=139.6 ; S D=125.2)$.

Parent's characteristics. Highest level of education (44.7\% - high school, 38.3\% - bachelor's degree; $17 \%$ master's degree or higher); employment (71.9\% -full-time, 22.1\%-part-time, 6\%-homemaker).

Family characteristics. Older siblings (yes $=51 \%$ ); number of different screen media devices in the household $(M=3.04 ; S D=1.05)$; TV set in child's bedroom (yes $=39 \%)$.

\section{Parents' attitudes towards media.}

Preferable platforms for children's viewing. Television, computer/laptop, tablet, smartphone and streaming media player - measured on a 4-point Likert scale from 1 ("not at all") to 4 ("very much"). As children may watch content via different devices, we did not insist that parents select a most preferable viewing platform, but offered a series of questions on each medium separately. On this basis, we created a score representing the parents' preference of digital media, calculated as an average of the items indicating preference towards PC/laptop, tablet, smartphone and streaming device $(M=2.38 ; S D=0.67$; Cronbach's alpha $=.748)$.

Parents' assessment of media's contribution to their children's development as a variation of Wartella and colleagues' (2013) measurement, posing four questions that inquire whether screen viewing enhances children's imagination, develops cognitive skills, enriches vocabulary and contributes to overall child development. Responses to all four questions were measured on a 4-point Likert scale ( $1=$ "not at all" to $4=$ "very much"). A media contribution score was then drawn up, based on the average of these items $(M=2.07 ; S D=0.89$; Cronbach's alpha $=.857$ ).

Parental concerns regarding media negative effects were assessed through seven items representing negative outcomes of media exposure identified in previous studies: Impaired motor skills, delayed language development, attention and concentration disorders, screen addiction, adversely affecting children's ability to occupy themselves independently, reducing parent-child activities and child's playtime (Christakis, Zimmerman, DiGiuseppe, \& McCarty, 2004; Vaala, 2014; Zimmerman \& Christakis, 2005). All items were measured on a 4 point Likert scale $(1=$ "not at all" to $4=$ "very much"). A media concerns score was calculated according to the average of these items $(M=2.65 ; S D=0.97 \text {; Cronbach's alpha }=0.678)^{1}$.

Parents' mediation was examined using items developed by previous studies on parental mediation of television content (e.g., Valkenburg, Kcrmar, Peeters, \& Marseille, 1999; Warren, 2003), distinguishing among three mediation styles:

Restrictive mediation was measured by three items, each representing a different aspect of parental efforts to limit children's media exposure and their access to inappropriate content. One item estimated whether the responding parent limits the child's total screen time $(M=2.57 ; S D=0.81)$, another examined whether the parent 
selects the child's viewing content $(M=3.08 ; S D=0.84)$; and the third evaluated the importance of the chosen content's being free of physical and verbal violence $(M=3.16 ; S D=0.72)$. All items were measured on a 4-point Likert scale ranging from 1 ("not at all") to 4 ("very much/often"). As each such mediation practice involves different considerations and constraints (e.g., parents could limit children's viewing time but not exert any significant efforts in selecting appropriate content, or vice versa), we examined the associations between each aspect of restrictive mediation and AOV separately.

Instructive mediation was represented by an item assessing whether or not responding parents use the content viewed to explain what children see on the screen and/or teach them something new $(M=2.76 ; S D=0.75)$, measured on a 4-point Likert scale ranging from 1 ("not at all") to 4 ("very often").

Co-viewing was measured according to two items, each representing a different co-viewing practice. One estimated whether parents watch child-oriented content with their children $(M=2.29 ; S D=1.12)$ and the other determined whether they allow children to join them in viewing adult programming $(M=1.96 ; S D=0.92)$. Both items were assessed on a 4-point Likert scale ranging from 1 ("not at all") to 4 ("very often").

Parental screen uses as part of their childrearing routine were inspired by nine common uses identified in previous studies: Keeping the child occupied, schedule regulation, calming, rewarding desired behavior, family time, screen viewing during meals, before bedtime, as a background for children's other activities and use of screen content for enrichment (e.g., Beyens \& Eggermont, 2014; Jordan et al., 2006; Rideout, 2013; Rideout \& Hamel, 2006; Wartella et al., 2013). To these uses, we added a tenth item especially typical of online viewing: Using screen content for children's entertainment outdoors (e.g., during trips or while waiting in public places). As it is important to identify the specific parental screen uses that contribute to greater online viewing time, the associations between the AOV and the ten screen uses were examined separately. All items were measured on a 2-point scale $\left(1=\right.$ "yes, at least several times a week" and $0=$ "very rarely or not at all"). ${ }^{2}$ The frequency of each use is presented in Table 1.

Table 1. Percentage of Parents Using Screen Viewing to Fulfill Childrearing Needs.

\begin{tabular}{lc}
\hline Screen Uses & $\%$ \\
\hline Calming device & 68.7 \\
Reward & 32.3 \\
Enrichment & 59.2 \\
Babysitter & 72.6 \\
Family time & 54.2 \\
Schedule regulation & 51.4 \\
During meals & 32.5 \\
Before bedtime & 37.1 \\
Outdoors & 43.3 \\
Background & 54.8 \\
Total & $100(N=289)$ \\
\hline
\end{tabular}

\section{Data Analysis}

Four research questions (RQ1-RQ4) were analyzed using bivariate correlations to characterize amount of online viewing (AOV) according to characteristics of the child, parent and family, as well as parents' attitudes and concerns towards media, mediation styles and use of screen viewing as part of their childrearing routines. The fifth research question was examined by a multiple linear regression aimed to identify the unique contribution of different predictors to the daily AOV. The following steps were taken to guarantee that the dataset fulfilled the requisite assumptions: a) Assessment of linear relationships between the independent and dependent variables, using scatterplots that tested all variables against the dependent one; b) Checking normal distribution of residuals by charting a histogram of residual values and comparing the line to a fitted normal distribution; c) Analyzing each variable's distribution and attributes and conducting a multicollinearity test for each set of 
variables to increase the effectiveness of prediction. Data were analyzed using SPSS v.23 software, with a confidence interval of $95 \%$ in all tests.

\section{Results}

First of all, the study shows a high rate of toddlers' AOV (i.e., amount of online viewing). On a typical day, $46.7 \%$ of children watched online content with an average viewing time of 46.8 minutes (SD 45 minutes), constituting one third of these children's total screen time. In addition, $20 \%$ of children watched online content at least occasionally (i.e., several times a month). Among online viewers, initial viewing begins during the first year of life, whereas by age 12 months, 52\% of children had viewed online content and by age 24 months - $91.5 \%$. All parents named YouTube as the most common viewing platform, whereas only a few (13\%) also mentioned official websites of children's television channels.

\section{Research Question 1}

In the first research question, we sought to characterize children's AOV according to their personal characteristics, as well as those of their respective parents and families. Among children's characteristics, only total screen time was significantly and positively correlated with AOV (see Table 2). Accordingly, there was a significant difference in total screen viewing between children who watch online content regularly and those who do not: Online viewers watch two hours and 39 minutes of screen content on a typical day, compared with one hour and 47 minutes for those who watch no online content. Parents' education and employment, presence of older siblings and number of different screen media in the household were not significantly associated with online viewing. By contrast, a TV set in the child's bedroom was positively associated with AOV: 60 minutes of online viewing on a typical day, compared with 38 minutes, respectively.

\section{Research Question 2}

The second research question aimed at identifying associations between parental attitudes towards media and children's AOV. First, there was a positive correlation between the score of parents' preference towards digital media and children's AOV, meaning that the children of parents who display a stronger preference toward digital viewing platforms are characterized by a higher AOV. Furthermore, there was a positive correlation between the media contribution score and children's AOV, meaning that parents of heavier online viewers perceive media effects as more beneficial towards children's development. On the other hand, the media concerns score was not significantly correlated with children's AOV (see Table 2).

\section{Research Question 3}

The third research question aimed at determining associations between children's AOV and the different types of parental mediation (see Table 2). There was a significant and negative correlation between the AOV and restrictive mediation of children's screen time and of content selection. That is, parents of heavier online viewers tend to be less restrictive with regard to children's screen time and selection of appropriate content. Furthermore, there was a negative association between the AOV and the importance ascribed by the parent to selection of content free of physical and verbal violence. Finally, there was a significant and positive correlation between AOV and co-viewing, both of content aimed at young children and of adult-oriented programs. Thus, children of more frequent co-viewers are characterized by greater online exposure.

\section{Research Question 4}

The fourth research question assessed children's AOV against parents' uses of screen viewing as part of their childrearing routines. Table 2 shows that nine out of ten uses were significantly and positively associated with children's AOV. Thus, parents of heavier online viewers have a stronger tendency to employ screen viewing for fulfilling a wide range of childrearing needs, such as using the screen as a babysitter, schedule regulation tool, calming device, during meals, before bedtime and the like. The only use that was not significantly associated with AOV was using screen content for children's enrichment. 


\begin{tabular}{lc}
\hline Independent variables & AOV \\
\hline Child, parent and family characteristics & .071 \\
Child's gender (1 = girl; 0 = boy) & -.033 \\
Child's age & $.636^{* *}$ \\
Child's total screen time & .048 \\
Parent's level of education & -.089 \\
Parent's employment & .073 \\
Older siblings (1 = yes; 0 = no) & .084 \\
Number of screen media devices & $.245^{* *}$ \\
TV in child's bedroom (1 = yes; 0 = no) & \\
Parental attitudes & $.166^{*}$ \\
Media contribution score & -.057 \\
Media concerns score & $.332^{* *}$ \\
Preference of digital media score & \\
Parental mediation & $-.134^{*}$ \\
Selection of content & $-.172^{* *}$ \\
Screen time restriction & $-.206^{* *}$ \\
Violence-free content & .118 \\
Instructive mediation & $.467^{* *}$ \\
Co-viewing of children's content & $.155^{*}$ \\
Co-viewing of adult content & \\
Screen uses (1 = yes, $\mathbf{0}=$ no) & $.197^{* *}$ \\
Calming device & $.189^{*}$ \\
Reward & .118 \\
Enrichment & $.212^{* *}$ \\
Babysitter & $.183^{* *}$ \\
Family time & $.296^{* *}$ \\
Schedule regulation & $.242^{* *}$ \\
During meals & $.217^{* *}$ \\
Before bedtime & $.151^{*}$ \\
Outdoors & $.255^{*}$ \\
Background &
\end{tabular}

Note: Spearman rank correlations were reported if one of the variables was not continuous. If any of the variables were dichotomous, a point-biserial correlation was used to measure the strength and direction of the associations. ${ }^{*} p<.05 * \star p<$ .01

\section{Research Question 5}

The fifth research question aimed at identifying the unique contribution of each predictor to the children's AOV while controlling for the influence of others. For this purpose, we conducted a multiple linear regression that revealed six predictors having a significant and positive effect (see Table 3): Parents' preference for digital media, co-viewing of children's content, using the screen as a babysitter, schedule regulation tool, family time and before bedtime. The regression analysis thus shows that children will watch more online content if their parents are more in favor of digital media as a preferable platform for screen viewing, if they have a stronger tendency to co-view child-oriented content and if they use screen viewing for family time, for keeping the child occupied, for regulating the child's daily schedule and for putting the child to bed. The overall regression model accounted for $36 \%$ of the variance. 


\begin{tabular}{|c|c|}
\hline Predictors & AOV \\
\hline \multicolumn{2}{|l|}{ Child, parent and family characteristics } \\
\hline Child's gender ( $1=$ girl; 0 = boy $)$ & .128 \\
\hline Child's age & -.120 \\
\hline Parent's level of education & .017 \\
\hline Parent's employment & -.080 \\
\hline Older siblings ( 1 = yes; 0 = no) & .079 \\
\hline Number of screen media devices & .035 \\
\hline TV in child's bedroom (1 = yes; 0 = no) & .091 \\
\hline \multicolumn{2}{|l|}{ Parental attitudes } \\
\hline Media contribution score & .014 \\
\hline Media concerns score & -.027 \\
\hline Preference of digital media score & $.226 * \star$ \\
\hline \multicolumn{2}{|l|}{ Parental mediation } \\
\hline Selection of content & -.081 \\
\hline Screen time restriction & -.041 \\
\hline Violence-free content & -.074 \\
\hline Instructive mediation & .049 \\
\hline Co-viewing of children content & $.196 *$ \\
\hline Co-viewing of adult content & .027 \\
\hline \multicolumn{2}{|l|}{ Screen uses $(1=$ yes; $0=$ no $)$} \\
\hline Calming device & .009 \\
\hline Reward & .100 \\
\hline Enrichment & .023 \\
\hline Babysitter & $.165^{\star}$ \\
\hline Family time & $.193^{*}$ \\
\hline Schedule regulation & $.206^{* *}$ \\
\hline During meals & .075 \\
\hline Before bedtime & $.167 *$ \\
\hline Outdoors & .073 \\
\hline Background & .035 \\
\hline$R 2 \quad .36$ & \\
\hline F $\quad 2.550$ & \\
\hline$d f \quad 26$ & \\
\hline
\end{tabular}

Note: ${ }^{*} \mathrm{p}<.05 * \star \mathrm{p}<.01 * \star \star \mathrm{p}<.001$

\section{Discussion and Conclusions}

For the first time, the present study sheds light on the online viewing patterns of a very young cohort: Toddlers aged 18 months to three years old. The study shows a high rate of online viewing, with almost half the children in the sample watching online content on a typical day. Initial viewing begins as early as the first year of life, supporting the assumption that children indeed go online at a much younger age (Holloway et al., 2013; Ólafsson, Livingstone, \& Haddon, 2014) - in this case, even before they could walk. Children's total screen time and the presence of a TV set in the child's bedroom were positively correlated with online viewing time. Accordingly, toddler online viewers may be characterized as heavy media consumers with less limited access to screen media.

Regarding parents' attitudes and mediation styles, we found that parents of heavier online viewers tend to be more positive about the media's contribution to children's development. On the other hand, parents' concerns regarding the negative effects of media were not associated with lower AOV. Furthermore, parents of online viewers tend to be less restrictive with regard to amount of viewing and content selection, underestimating the importance of selecting content free of violent expressions. These findings are particularly alarming, as they imply that very young children may be exposed to harmful content during unsupervised online viewing. They 
also conform with findings of previous studies on children's online safety, indicating that parents of younger children are less concerned about the possible online risks their children may encounter (see, Chaudron, 2015; Holloway et al., 2013; Plowman et al., 2010).

Additionally, parents of heavier online viewers tend to be more frequent co-viewers of child and adult-oriented content alike, whereas their inclination towards instructive mediation was not associated with AOV. These patterns confirm the findings of previous studies on children's general screen viewing (e.g., Johnson et al., 2015; Vaala et al., 2013; Valkenburg et al., 1999; Warren, 2003), indicating that parents tend to employ similar mediation efforts towards online viewing as they apply to television. Parents thus overlook significant differences between the two in terms of access and content variety alike.

Finally, parents of heavier online viewers tend to use screen content to fulfill a broad range of childrearing needs, with only one exception: Using the screen for children's enrichment. It appears, therefore, that parents have yet to discover the enriching opportunities of online viewing platforms, employing them instead for instrumental motives entrenched in their parental routine. Although parental use of touchscreens as a "digital pacifier" was indeed documented in previous studies (e.g., Hiniker et al., 2016; Kabali et al., 2015; Wartella et al., 2013), our findings add a further important dimension to this corpus of knowledge, as they reveal a variety of parents' instrumental uses and how they are related to the children's AOV.

Alongside an initial effort to characterize toddlers' AOV according to its correlations with different sets of variables, the present study has attempted to explain it by identifying a unique contribution of each predictor while controlling for the influence of others. The regression findings show that except for two predictors that reflect parents' preference towards digital media and their co-viewing attempts, all other significant predictors are driven by childrearing needs: Using screen viewing as a babysitter, schedule regulation, family time and before bedtime.

Although the contribution of parents' babysitting needs to children's screen time was already found with regard to television (e.g., Beyens \& Eggermont, 2014; Gantz \& Masland, 1986), using online viewing for this purpose means that the stand-by digital babysitter can accompany the child anywhere in the house, as well as away from home. These findings may have significant long-term implications for the growing amount of young children's media exposure, as well as for parent-child relations and overall child development, as the facility with which online content may be viewed virtually everywhere might reduce opportunities for parent-child interaction and bonding.

The positive effect of screen viewing before bedtime on AOV is no less disturbing, especially given the high mobility of internet-connected devices. We may easily assume that children might watch online content in bed, supplanting traditional book reading by parents. This finding is particularly alarming in light of a recently published study noting that infants and toddlers who spend more time using a touchscreen device sleep less at night and take longer to fall asleep (Cheung et al., 2017).

Furthermore, use of screen viewing as a schedule regulation tool implies that parents find it useful for setting points marking transition from one phase to another. At the same time, use of online content to regulate children's daily schedules contributes to a higher AOV. This finding is related to certain features of online viewing platforms that render it more difficult for parents to set limits on their children's screen time (Hiniker et al., 2016). Another finding of the present study supports this assumption, demonstrating that within the regression model, parents' restrictive mediation did not have a significant effect on children's AOV. Hence, it is possible that parents manage their children's daily schedule successfully with the help of online media devices, yet fail to regulate the amount of the children's media exposure.

Accordingly, the results of this study attest to the unique characteristics of online viewing platforms that might reinforce parents' dependence on digital media as an all-in-one parental aid. Moreover, childrearing needs appear to outweigh other amount of viewing predictors found in previous studies, such as parental attitudes towards media. Thus, whether or not parents display positive attitudes towards media and whether or not they are concerned about their negative effects, what tips the scale in favor of extended online viewing is the challenge of multitasked parenting. In this sense, the present study not only reveals that online viewing has 
become normative behavior among toddlers, but also emphasizes how deeply it is integrated into the basic daily routine of parents with very young children. This situation evokes a basic need for informative campaigns directed at parents, who require tools to help them select online content that provides their children with a safe and enriching environment, even if their objectives for children's screen viewing are primarily instrumental.

\section{Limitations and Future Research}

The chief limitation of this study is its having based estimates of children's online viewing on parents' selfreporting. While parental reporting is common in studies of this type, it may engender underestimation, as parents might adjust their estimates following repeated warnings of the negative outcomes associated with high media exposure. In this study, however, the method provided the best measure possible, as its groundbreaking objective was characterization of toddlers' online viewing according to different sets of predictors, such as characteristics of children, parents and families, parental attitudes and mediation styles and parents' screen uses as part of their childrearing routine. Inaccuracies in estimation of AOV may be overcome in a follow-up study based on a combination of survey and media diaries. We also attempted to reduce the effects of constraints inherent in the convenience sample of parents by applying quotas of girls and boys and of three subgroups of children's ages.

As the study was conducted in Israel, a more global assessment of young children's online viewing would have much to offer in terms of understanding its place in children's life. Furthermore, as the study focused exclusively on parents of toddlers, future research should address a wider range of children's ages to examine parental needs responsible for children's AOV across various stages of childhood. Notwithstanding the limitations stipulated, this study outlined a new and important dimension of very young children's media exposure that should be considered in future research aimed at explaining children's contemporary media habits.

\section{Notes}

1. As the alpha value was lower than 0.7, Tavakol and Dennick's (2011) method for brief measurements was applied by checking the correlation of each item with the total score (the average rankings for all items). All displayed very high correlations and thus no item was deleted.

2. Originally these items were measured on a 4-point Likert scale, but we replaced it with a dichotomous scale after participants in the pilot study experienced difficulty estimating the precise frequency of a certain practice, characterizing it as either common (in use on a daily basis or several times a week) or very rare/not in use.

\section{Acknowledgements}

This research was supported by the I-CORE Program of the Planning and Budgeting Committee and The Israeli Science Foundation (1716/12).

The article's title is inspired by Lemish, D. (1987). Viewers in Diapers: The Early Development of Television Viewing. In T.R. Lindlof (ed.), Natural audiences: qualitative research of media uses and effects (pp. 33-57). Norwood, NJ: Ablex.

\section{References}

Anand, S., \& Krosnick, J. A. (2005). Demographic predictors of media use among infants, toddlers, and preschoolers. American Behavioral Scientist, 48, 539-561. https://doi.org/10.1177/0002764204271512

Beyens, I., \& Eggermont, S. (2014). Putting young children in front of the television: Antecedents and outcomes of parents' use of television as a babysitter. Communication Quarterly, 64, 57-74.

https://doi.org/10.1080/01463373.2013.860904 
Buzzi, M. (2011). What are your children watching on YouTube? In V. F. Cipolla, K. V. Ficarra, \& D. Verber (Eds.), Advances in new technologies interactive interferences and communicability (pp. 243-252). Berlin, Germany: Springer.

Cantor, P. A., \& Cornish, M. M. (2016). Techwise infant and toddler teachers: Making sense of screen media for children under 3. Information Age Publishing.

Chaudron, S. (2015). Young children (0-8) and digital technology - EU report. Luxembourg: Publications Office of the European Union. Retrieved from http://publications.jrc.ec.europa.eu/repository/bitstream/JRC93239//bna27052enn.pdf

Cheung, C. H. M., Bedford, R., Saez De Urabain, I. R., \& Karmiloff-Smith, A. (2017). Daily touchscreen use in infants and toddlers is associated with reduced sleep and delayed sleep onset. Scientific Reports, 7, article 46104. Retrieved from https://www.nature.com/articles/srep46104

Christakis, A. C., Zimmerman, F. J., DiGiuseppe, D. L., \& McCarty, C. A. (2004). Early Television exposure and subsequent attentional problems in children. Pediatrics, 113, 708-713. https://doi.org/10.1542/peds.113.4.708

DeHart, G. B., Sroufe, L. A., \& Cooper, R. G. (2004). Child development, its nature and course (5 $5^{\text {th }}$ ed.). New York, USA: McGraw-Hill Humanities Social.

Dredge, S. (2015, November 19). Why YouTube is the new children's TV and why it matters. The Guardian. Retrieved from http://www.theguardian.com/technology/2015/nov/19/youtube-is-the-new-childrens-tv-hereswhy-that-matters

Dürager, A., \& Livingstone, S. (2012). How can parents support children's internet safety? London, UK: EU Kids Online. Retrieved from http://eprints.Ise.ac.uk/id/eprint/42872

Elias, N., Sulkin, I., \& Lemish, D. (in press). Gender segregation on BabyTV: Old-time stereotypes for the very young. In D. Lemish \& M. Gotz (Eds.), Beyond the stereotypes: Boys, girls and their images. Nordicom.

Fox, A. (2014, March 26). The Israelis that conquered toddlers around the world. Mako Magazine. Retrieved from http://www.mako.co.il/home-family-weekend/Article-a4dda21f12ef441006.htm

Gantz, W., \& Masland, J. (1986). Television as Babysitter. Journalism Quarterly, 63, 530-536. https://doi.org/10.1177/107769908606300312

Gentile, D. A., \& Walsh, D. A. (2002). A normative study of family media habits. Applied Developmental Psychology, 23, 157-178. https://doi.org/10.1016/S0193-3973(02)00102-8

Golin, J., Chester, F., \& Campbell, A. (2015, April 7). Advocates file FTC complaint against Google's YouTube Kids. Campaign for a Commercial-Free Childhood. Retrieved from http://www.commercialfreechildhood.org

Grossaug, R. (2017). What influences the influencers: Preschool television production in an era of media change: The case of Israel's 'Hop! Group' [Unpublished doctoral dissertation]. The Hebrew University of Jerusalem.

Hasebrink, U., Görzig, A., Haddon, L., Kalmus, V., \& Livingstone, S. (2011). Patterns of risk and safety online: Indepth analyses from the EU Kids Online survey of 9- to 16-year-olds and their parents in 25 European countries. London, UK: EU Kids Online. Retrieved from http://eprints.Ise.ac.uk/39356/

Hiniker, A., Suh, H., Cao, S., \& Kientz, J. A. (2016). Screen time tantrums: How families manage screen media experiences for toddlers and preschoolers. In Proceedings of the 2016 CHI Conference on Human Factors in Computing Systems (pp. 648-660). Retrieved from http://www.researchgate.net/publication/290393196_Screen_Time_Tantrums_How_Families_Manage_Screen_Me dia_Experiences_for_Toddlers_and_Preschoolers

Holloway, D., Green, L., \& Livingstone, S. (2013). Zero to eight. Young children and their internet use. London, UK: EU Kids Online. Retrieved from http://eprints.Ise.ac.uk/52630/1/Zero_to_eight.pdf 
Holloway, D., Green, L., \& Love, C. (2014). "It's all about the apps": Parental mediation of their preschoolers' digital lives. Media International Australia, Incorporating Culture \& Policy, 153, 148-156.

https://doi.org/10.1177/1329878x1415300117

Holloway, D., Green, L., \& Stevenson, K. (2015). Digitods: Toddlers, touch screens and Australian family life. M/C Journal: A Journal of Media and Culture, 18(5). Retrieved from http://journal.media-

culture.org.au/index.php/mcjournal/article/view/1024

Israel Central Bureau of Statistics. (2011). Men and women in Israel: 1999-2011 (in Hebrew). Retrieved from http://www.cbs.gov.il/www/statistical/mw2013_h.pdf

Johnson, L., Chen, T. A., Hughes, H. O., \& O'Connor, T. M. (2015). The association of parent's outcome expectations for child TV viewing with parenting practices and child TV viewing: An examination using path analysis. International Journal of Behavioral Nutrition and Physical Activity, 12, article 70.

https://doi.org/10.1186/s12966-015-0232-2

Jordan, A. B. (2004). The role of media in children's development: An ecological perspective. Journal of Developmental \& Behavioral Pediatrics. 25, 196-206. https://doi.org/10.1097/00004703-200406000-00009

Jordan, A. B. (2015, November). Digital natives and digital immigrants: Media use and generational identity. Keynote lecture. Ben-Gurion University of the Negev, Beer- Sheva, Israel.

Jordan, A. B., Hersey, J. C., McDivitt, J. A., \& Heitzler, C. D. (2006). Reducing children's television-viewing time: A qualitative study of parents and their children. Pediatrics, 118, 1303-1310. https://doi.org/10.1542/peds.20060732

Kabali, K. H., Irigoyen, M. M., Nunez-Davis, R., Budacki, G. J., Mohanty, H. S., Leister, P. K., \& Bonner, L. R. (2015). Exposure and use of mobile devices by young children. Pediatrics, 136, 1044-1050.

https://doi.org/10.1542/peds.2015-2151

Kaspersky Lab, (2013, February 5). Children at High Risk of Accessing Adult Content on YouTube. PRNewswire. Retrieved from http://www.prnewswire.com/news-releases/children-at-high-risk-of-accessing-adult-content-onyoutube-189770621.html

Knorr, C. (2016, March 15). What kids are really watching on YouTube? Common Sense Media. Retrieved from http://www.commonsensemedia.org/blog/what-kids-are-really-watching-on-youtube

Kucirkova, N. (2011). Digitalised early years - where next? New Voices, 24, 938-940.

Livingstone, S., Haddon, L., Görzig, A., \& Ólafsson, K. (2011). Risks and safety on the internet: The perspective of European children. London, UK: EU Kids Online. Retrieved from http://eprints.Ise.ac.uk/33731

Livingstone, S., Marsh, J., Plowman, L, Ottovordemgentschenfelde, S., \& Fletcher-Watson, B. (2014). Young children (0-8) and digital technology: A qualitative exploratory study - national report - UK. Luxembourg: Joint Research Centre, European Commission. Retrieved from http://eprints.Ise.ac.uk/60799

Luckerson, V. (2013, March 13). How Sesame Street Counted All the Way to 1 Billion YouTube Views. Time. Retrieved from http://business.time.com/2013/03/15/how-sesame-street-counted-all-the-way-to-1-billionyoutube-views

Luscombe, B. (2015, September 7). YouTube view's master. Time, 70-75.

Mako magazine (2016, November 14). Not for the kids: Sexual content in Spiderman video clips. Mako magazine. Retrieved from http://www.mako.co.il/tv-live-at-night/articles/Article-4bd474fe69f5851006.htm

Man, R., \& Lev-On, A. (2015). Media uses in Israel 2015: Data and tendencies. Institute of new media, society and politics. Ariel (in Hebrew). Retrieved from

http://aunmedia.org/sites/default/files/research/mr2015/MediaReport2015\%20Ch2.pdf

Marsh, J. (2016). Unboxing' videos: Co-construction of the child as cyberflaneur. Discourse: Studies in the cultural politics of education, 37, 369-380. https://doi.org/10.1080/01596306.2015.1041457 
Marsh, J., Hannon, P., Lewis, M., \& Ritchie, L. (2017). Young children's initiation into family literacy practices in the digital age. Journal of Early Childhood Research, 15, 47-60. https://doi.org/10.1177/1476718X15582095

Miner, R. (2015). Television is now the second screen for kids with tablets [Survey report]. Retrieved from http://www.minerandcostudio.com/tv-is-now-the-second-screen

Morrongiello, B. A., Corbett, M., McCourt, M., \& Johnston, N. (2006). Understanding unintentional injury risk in young children: The contribution of caregiver supervision, child attributes, and parent attributes. Journal of Pediatric Psychology, 31, 540-551. https://doi.org/10.1093/jpepsy/jsj073

Nikken, P., \& de Haan, J. (2015). Guiding young children's internet use at home: Problems that parents experience in their parental mediation and the need for parenting support. Cyberpsychology: Journal of Psychosocial Research on Cyberspace, 9(1), article 3. http://dx.doi.org/10.5817/CP2015-1-3

Nimrod, G., Adoni, H., \& Nossek, H. (2015). The internet as a cultural forum: A European perspective. International Journal of Communication, 9, 321-341.

Ofcom. (2014). Children and parents: Media use and attitudes report. Ofcom. Retrieved from www.ofcom.org.uk/_data/assets/pdf_file/0027/76266/childrens_2014_report.pdf

Ólafsson, K., Livingstone, S. \& Haddon, L. (2014) Children's use of online technologies in Europe: A review of the European evidence database. Retrieved from

http://eprints.Ise.ac.uk/60221/

Piotrowski, J. T., Jordan, A. B., Bleakley, A., \& Hennessy, M. (2015). Identifying family television practices to reduce children's television time. Journal of Family Communication, 15, 159-174.

https://doi.org/10.1080/15267431.2015.1013107

Plowman, L., McPake, J., \& Stephen, C. (2010). The technologisation of childhood? Young children and technology in the home. Children \& Society, 24, 63-74. https://doi.org/10.1111/j.1099-0860.2008.00180.x

Radesky, J. S., Kistine, C. J., Zukerman, B., Nitzberg, K., Gross, J., Kaplan-Snoff, M., . . Silverstein, M. (2014). Patterns of mobile device use by caregivers and children during meals in fast food restaurants. Pediatrics, 133, 845-849. https://doi.org/10.1542/peds.2013-3703

Rideout, V. (2013, October 28). Zero to eight: Children's media use in America in 2013. Common Sense Media. Retrieved from http://m.commonsensemedia.org/sites/default/files/research/zero-to-eight-2013.pdf

Rideout, V. J., \& Hamel, E. (2006, May 1). The media family: Electronic media use in the lives of infants, toddlers, preschoolers and their parents. The Henry J. Kaiser Family Foundation. Retrieved from http://kaiserfamilyfoundation.files.wordpress.com/2013/01/7500.pdf

Schmitt, K. M. (2001). Infants, toddlers, and television: The ecology of the home. Zero to Three, 22(2), 17-23.

Sol, C. (2017, January 17). Let's help you to get rid from the odd video clips of Elsa and Spiderman. Mako Magazine. Retrieved from http://www.mako.co.il/nexter-cellular/Article-bdbae3cdbc1a951006.htm

Stephen, C., Stevenson, O., \& Adey, C. (2013). Young children engaging with technologies at home: The influence of family context. Journal of Early Childhood Research, 11, 149-164. https://doi.org/10.1177/1476718X12466215

Tavakol, M., \& Dennick, R. (2011). Making sense of Cronbach's alpha. International Journal of Medical Education, 2, 53-55. https://doi.org/10.5116/ijme.4dfb.8dfd

Vaala, S. E. (2014). The nature and predictive value of mothers' beliefs regarding infants' and toddlers' TV/Video viewing: Applying the integrative model of behavioral prediction. Media Psychology, 17, 282-310.

https://doi.org/10.1080/15213269.2013.872995

Vaala, S. E., Bleakley, A., \& Jordan, A. B. (2013). The media environments and television-viewing diets of infants and toddlers: Findings from a national survey of parents. Zero to Three, 33(4), 18-24. 
Vaala, S. E., \& Hornik, R. C. (2014). Predicting US infants' and toddlers' TV/Video viewing rates: Mothers' cognitions and structural life circumstances. Journal of Children and Media, 8, 163-182.

https://doi.org/10.1080/17482798.2013.824494

Valkenburg, P. M., Krcmar, M., Peeters, A. L., \& Marseille, N. M. (1999). Developing a scale to assess three styles of television mediation: "Instructive mediation," "restrictive mediation," and "social coviewing." Journal of Broadcasting \& Electronic Media, 43, 52-66. https://doi.org/10.1080/08838159909364474

Vandewater, E. A., \& Lee, S. J. (2009). Measuring children's media use in digital age. American Behavioral Scientist, 52, 1152-1176. https://doi.org/10.1177/0002764209331539

Warren, R. (2003). Parental mediation of preschool children's television viewing. Journal of Broadcasting \& Electronic Media, 47, 394-417. https://doi.org/10.1207/s15506878jobem4703_5

Wartella, E., Rideout, V., Lauricella, A. J., \& Connell, S. L. (2013). Parenting in the age of digital technology: A national survey. Centre of Media and Human Development, Northwestern University. Retrieved from http://cmhd.northwestern.edu/wp-

content/uploads/2015/06/ParentingAgeDigitalTechnology.REVISED.FINAL_.2014.pdf

Zack, E., \& Barr, R. (2016). The role of interactional quality in learning from touch screens during infancy: Context matters. Frontiers in Psychology, 7, article 1264. Retrieved from

https://www.ncbi.nlm.nih.gov/pmc/articles/PMC5003922

Zaman, B., Nouwen, M., Vanattenhoven, J., de Ferrerre, E., \& Van Looy, J. (2016). A qualitative inquiry into the contextualized parental mediation practices of young children's digital media use at home. Journal of Broadcasting \& Electronic Media, 60, 1-22. https://doi.org/10.1080/08838151.2015.1127240

Zimmerman, F. J., \& Christakis, A. C. (2005). Children's television viewing and cognitive outcomes: A longitudinal analysis of national data. Archives of pediatrics \& Adolescent Medicine, 159, 619-625.

https://doi.org/10.1001/archpedi.159.7.619

\section{Correspondence to:}

Nelly Elias

Department of Communication Studies

Ben-Gurion University of the Negev

Beer-Sheva 84105

Israel

Email: enelly(at)bgu.ac.il

Editorial record: First submission received on April 29, 2017. Revisions received on July 17, 2017 and July 21, 2017. Accepted for publication on July 24, 2017.

The article is part of the Special Issue "Young children's use of digital media and parental mediation" guest edited by Bieke Zaman and Charles Mifsud. 


\section{About Authors}

Nelly Elias (Ph.D.) is an Associate Professor in the Department of Communication Studies at Ben-Gurion University of the Negev. Her primary research interests include media and migration and media and children. She is a member of the LINKS (Learning in a NetworKed Society) Center for Research Excellence, where she conducts a series of projects on infants and toddlers' media uses in a changing technological environment.

Idit Sulkin (Ph.D.) is an Adjunct Lecturer in the Department of Communication Studies at Ben-Gurion University of the Negev. Her research focuses on screen content effects on infants' and toddlers' development, the role of music and presentation style in reducing the screen deficit effect and family relations affected by media use. She also develops, writes and produces programs for children's channels in Israel. 